\title{
Effect of TSLC1 gene on growth and apoptosis in human esophageal carcinoma Eca109 cells
}

\author{
Qi-Lian Liang'1, Bi-Rong Wang², Zhou-Yu Li', Guo-Qiang Chen'1 Yuan Zhou'
} 1Department of Oncology, Affiliated Hospital of Guangdong Medical College, Zhanjiang,
China
2Department of Chemotherapy, Affiliated Tumor Hospital of Guangzhou Medical College,
Guangzhou, China
3Department of Radiotherapy, Affiliated Tumor Hospital of Guangzhou Medical College,
Guangzhou, China

Submitted: 24 July 2011

Accepted: 2 January 2012

Arch Med Sci 2012; 8, 6: 987-992

DOI: 10.5114 /aoms.2012.31251

Copyright $\odot 2012$ Termedia \& Banach

\begin{abstract}
Introduction: To explore the effect of tumor suppressor in lung cancer 1 (TSLC1) on proliferation and apoptosis in esophageal cancer Eca109 cells.

Material and methods: Eca109 cells were divided into three groups: TSLC1 transfected group (TTG), mock group (MG) and untransfected group (UTG). The TTG and MG were transfected transiently with the pIRES2-EGFP-TSLC1 eukaryotic expression vector and pIRES2-EGFP vector respectively. The UTG was a blank control. The TSLC1 expression in TTG was analyzed with the fluorogram and RT-PCR method. Cell proliferation was measured with 3-(4,5-dimethyl-2-thiazolyl)2,5-diphenyl-2H-tetrazolium (MTT) assay. Cell cycle was measured by flow cytometry (FCM). Cell apoptosis was detected by Annexin-V/PI double staining FCM. Results: Green color was found in TTG and MG. The band of TSLC1 mRNA of TTG was located at about 1400 bp by RT-PCR and agarose gel electrophoresis assay. The TSLC1 inhibited cell proliferation significantly in MTT assay, and the cell proliferation was slower in TTG than MG and UTG. After TSLC1 transfection, cell numbers increased in G0/G1 phase and decreased in S phase. Forty-eight hours after transfection, the apoptosis rate and death rate of TTG were higher than MG and UTG. Thus TSLC1 induced Eca109 cells to apoptosis.

Conclusions: The TSLC1 gene had a potent effect on cell proliferation inhibition, G1/S cell cycle arrest and induction of cell apoptosis in Eca109 cells.
\end{abstract}

Key words: esophageal carcinoma, TSLC1 gene, transient transfection, cell cycle, apoptosis.

\section{Introduction}

Tumor suppressor in lung cancer 1 (TSLC1) was originally isolated from non-small cell lung cancer as a potential tumor suppressor gene [1, 2]. This gene is mapped to human chromosome 11q23.2 and spans over $300 \mathrm{~kb}$ with 10 exons, which encode a 4.4 or $1.6 \mathrm{~kb}$ mRNA sequence; it can be translated into a 442 amino acid transmembrane glycoprotein. TSLC1 protein contains three domains, extracellular, transmembrane and intracellular, which may correlate with its function. TSLC1 expression is down-regulated in many human cancers, such as laryngeal squamous carcinoma [3], uterine cervix cancer [4], ovarian carcinoma [5], breast cancer [6], nasopharyngeal carcinoma [7] and neuroblastoma [8]. It has been found

\section{Corresponding author:}

Prof. Qi-Lian Liang

Department of Oncology

Affiliated Hospital

of Guangdong

Medical College

57 People Avenue

Zhanjiang 524001

Guangdong, China

Phone: 86-759-2387455

Fax: 86-759-2231754

E-mail: lianqilian@gdmc.edu.cn 
that the lack of TSLC1 expression is closely related to the occurrence and progression of these cancers. However, so far, the mechanism of TSLC1 gene is not clear. It is considered that it may play its role by inducing cancer cells to apoptosis and arresting the cell cycle [9]. Esophageal cancer is one of the most common cancers in the world. It has a poor response to treatment and high mortality. Despite recent advances in chemotherapy and radiotherapy, esophageal cancer is still a tough problem with little progress in adjuvant therapy. To improve this situation, it is necessary to explore new molecular mechanisms further. Ito et al. [10] confirmed that the TSLC1 gene lacked expression or was lowly expressed in Eca109 cells. Therefore, we decided to explore whether TSLC1 can also inhibit proliferation and induce apoptosis in Eca109 cells.

\section{Material and methods}

\section{Reagents and cell line}

Neonatal calf serum (NCS), phosphate buffered saline (PBS), RPMI-1640 medium and DMSO were purchased from Hangzhou Sijiqing Bio Co, Ltd (China). Lipofectamine 2000 was bought from Invitrogen CO (USA). 3-(4,5-dimethyl-2-thiazolyl)-2,5diphenyl-2H-tetrazolium (MTT) was from Shanghai Public Health Bio-Engineering Co, Ltd (China). Annexin V-fluorescein isothiocyanate (FITC)/PI reagent Kit, RNase $A$ and plasmid mini preparation kit were from Beyotime Institute of Biotechnology (China). Reverse transcript polymerase chain reaction (RT-PCR) Reagents Kit and DL2, 000 DNA Marker were from TaKaRa Biotech Ltd (China). Primers were synthesized by TaKaRa Biotech Ltd (China). Human esophageal carcinoma Eca109 cell line was purchased from China Center for Typical Culture Collection (China). It was cultured in RPMI-1640 medium supplemented with $10 \% \mathrm{NCS}, 100 \mathrm{U} / \mathrm{ml}$ penicillin, $100 \mu \mathrm{g} / \mathrm{ml}$ streptomycin and maintained in a $5 \% \mathrm{CO}_{2}$ humidified atmosphere at $37^{\circ} \mathrm{C}$.

\section{Plasmid and cell transfection}

The plasmid pIRES2-EGFP was presented as a gift from the Biochemistry Laboratory of Guangdong Medical College. The plasmid pIRES2-EGFP-TSLC1 eukaryotic expression vector was constructed by our laboratory [11]. Eca109 cells were divided into three groups: TSLC1 transfected group (TTG), mock group (MG), and untransfected group (UTG). MG and TTG were transiently transfected with plasmid pIRES2-EGFP and plasmid pIRES2-EGFP-TSLC1 with Lipofectamine 2000 respectively, according to the manufacturer's instructions, and UTG did not receive any treatment.

\section{RNA extraction and RT-PCR assay}

Total RNA was extracted from TTG $48 \mathrm{~h}$ after transient transfection using the Trizol kit, according to the manufacturer's instructions. RT-PCR used RNA which was from Eca109-TSLC1 clones (TTG) and primers OUTER F 5'-GCGTGGGGTGCCCGACATGG-3'20 mers and OUTER R 5'-AAATAGGGCCAGTTGGACAC-3' 20 mers. The PCR conditions were 30 cycles of $94^{\circ} \mathrm{C}$ $3 \mathrm{~min}, 98^{\circ} \mathrm{C} 10 \mathrm{~s}, 55^{\circ} \mathrm{C} 15 \mathrm{~s}$, and $72^{\circ} \mathrm{C} 1 \mathrm{~min}$, with a final extension at $72^{\circ} \mathrm{C}$ for $10 \mathrm{~min}$. The RT-PCR products were analyzed by $1.5 \%(\mathrm{w} / \mathrm{v})$ agarose gel electrophoresis.

\section{Cell proliferation assay}

Morphological changes of cells were observed under an inverted microscope $48 \mathrm{~h}$ after transient transfection. The anti-proliferative effect of TSLC1 on Eca109 cells was determined by the MTT method. Briefly, Eca109 cells were maintained in RPMI-1640 medium until mid-log phase and plated in a 96-well plate $\left(1 \times 10^{3}\right.$ per well $)$, and divided into three groups (each group had three wells). The TTG and $M G$ were treated as before. The plates were cultured for 12 h, 24 h, 36 h, 48 h, 60 h and 72 h. At each time point, MTT dye was added to each well $(5 \mathrm{mg} / \mathrm{ml})$. After $3 \mathrm{~h}$, the crystal was dissolved in $0.15 \mathrm{ml}$ DMSO. Optical density (OD) value at $490 \mathrm{~nm}$ was measured using an enzyme-labeled meter (Japan). Cell proliferation was calculated according to this formula: cell proliferation inhibition rate $=((\mathrm{OD}$ value of MG - OD value of TTG)/OD value of $M G$ ) $\times 100 \%$. This procedure was repeated three times.

\section{Cell cycle analysis}

The Eca109 cell was incubated in a 6-well cell culture cluster $\left(1 \times 10^{6}\right.$ per well), and divided into three groups. TTG and MG were treated as before. $48 \mathrm{~h}$ after transfection, all cells were collected, washed with PBS, and then suspended in $70 \%$ ethanol at $4^{\circ} \mathrm{C}$ overnight. Cells were incubated with $6 \mu \mathrm{l}$ of $1 \mathrm{~g} / \mathrm{l}$ RNase $\mathrm{A}, 1 \mathrm{ml}$ of $1 \mathrm{mg} / \mathrm{ml} \mathrm{PI}$ and $400 \mu \mathrm{l}$ of PBS at room temperature for $15 \mathrm{~min}$. DNA content was analyzed by FCM. This procedure was repeated three times.

\section{Annexin V-FITC/PI double-labeled flow cytometry}

The pre-processing of the three groups was the same as cell cycle analysis. Forty-eight hours after transfection, all cells were collected and washed with PBS twice. Cells were incubated with AnnexinV-FITC in the dark at room temperature for $10 \mathrm{~min}$, then PI was added and cells were incubated for another $10 \mathrm{~min}$ in the dark at room temperature. Cell apoptosis was measured by FCM. This procedure was repeated three times.

\section{Statistical analysis}

All experiments were repeated three times. All data are expressed as mean \pm standard deviation 

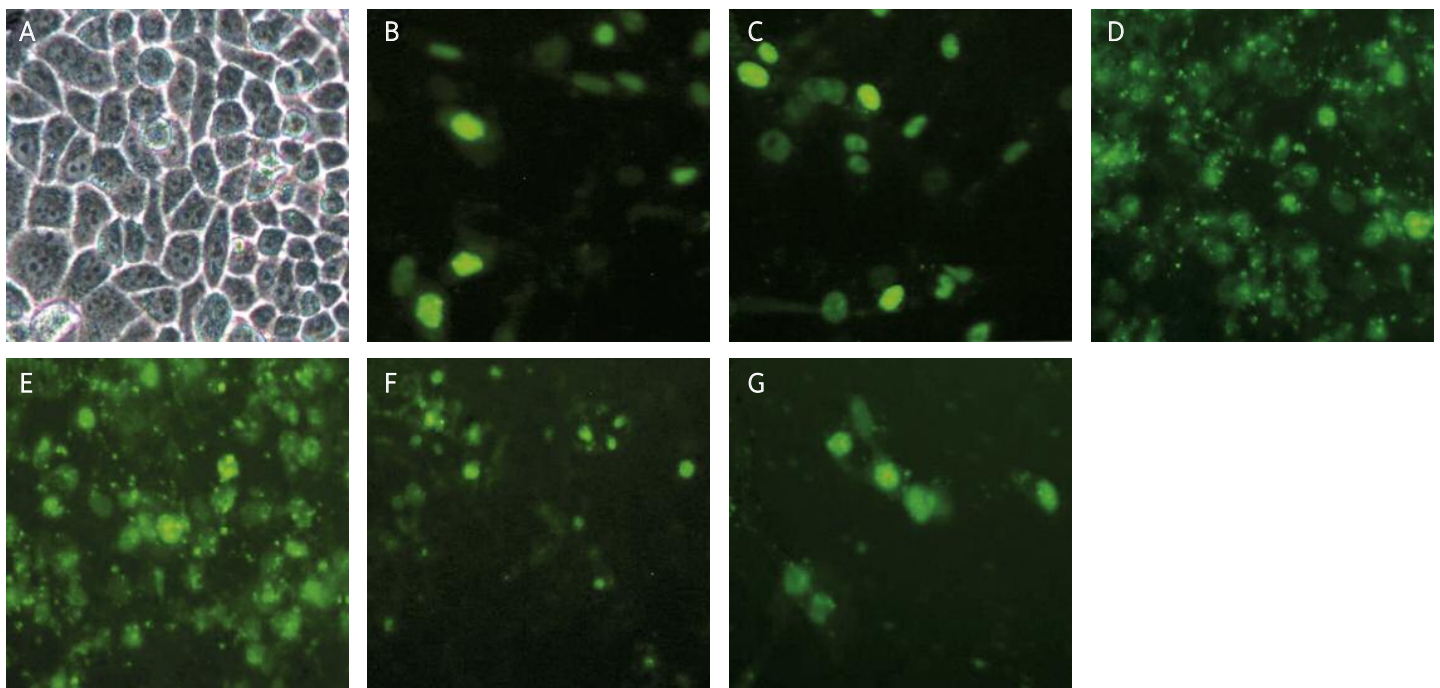

Figure 1. Fluorogram after transient transfection. A - UTG, B - M group $24 \mathrm{~h}$ after transient transfection, $\mathrm{C}-\mathrm{TT}$ group $24 \mathrm{~h}$ after transient transfection, D - M group $48 \mathrm{~h}$ after transient transfection, $\mathrm{E}-\mathrm{TT}$ group $48 \mathrm{~h}$ after transient trans fection, $\mathrm{F}-\mathrm{M}$ group $72 \mathrm{~h}$ after transient transfection, $\mathrm{G}-\mathrm{TT}$ group $72 \mathrm{~h}$ after transient transfection (original magnification 200x)

$(\bar{x} \pm s)$. Data were analyzed using SAS 8.0 software. Student $t$-test, $q$ test and rank sum test were applied for comparison between two groups as necessary. Value of $p<0.05$ indicated a significant difference.

\section{Results}

\section{Expression and identification of TSLC1 gene}

Twenty-four hours, $48 \mathrm{~h}$ and $72 \mathrm{~h}$ after being transiently transfected with plasmid pIRES2-EGFP and plasmid pIRES2-EGFP-TSLC1, the three groups were observed by using a fluorescence microscope. Green color was found in TTG and MG, but not in UTG. Forty-eight hours after transfection, the brightest fluorescence was seen in MG and TTG (Figure 1). The expression band of TSLC1 mRNA (TTG) was located at about 1400 bp by RT-PCR (Figure 2).

\section{Morphological changes}

Cell growth was inhibited significantly in TTG, which showed round and oval-shaped cells, clustered into a mass, scattered between cell mass and in a poor state $48 \mathrm{~h}$ after transfection. Polygonal and spindle cells, packed closely together between cells and eugonic growth were found in MG and UTG (Figure 3).

\section{Effect of TSLC1 on proliferation of Eca109 cells}

The OD value of each well was obtained by measuring all groups every $12 \mathrm{~h}$ from the first day after transfection, for $72 \mathrm{~h}$ at a stretch. Cell proliferation curves were depicted with the mean OD value of each time point (Figure 4). The growth inhibition rate for each time point of TTG was calculated according to the formula given above. It indicated that the cell proliferation was slower in TTG than both MG and UTG $(p<0.05$, Table I). The growth

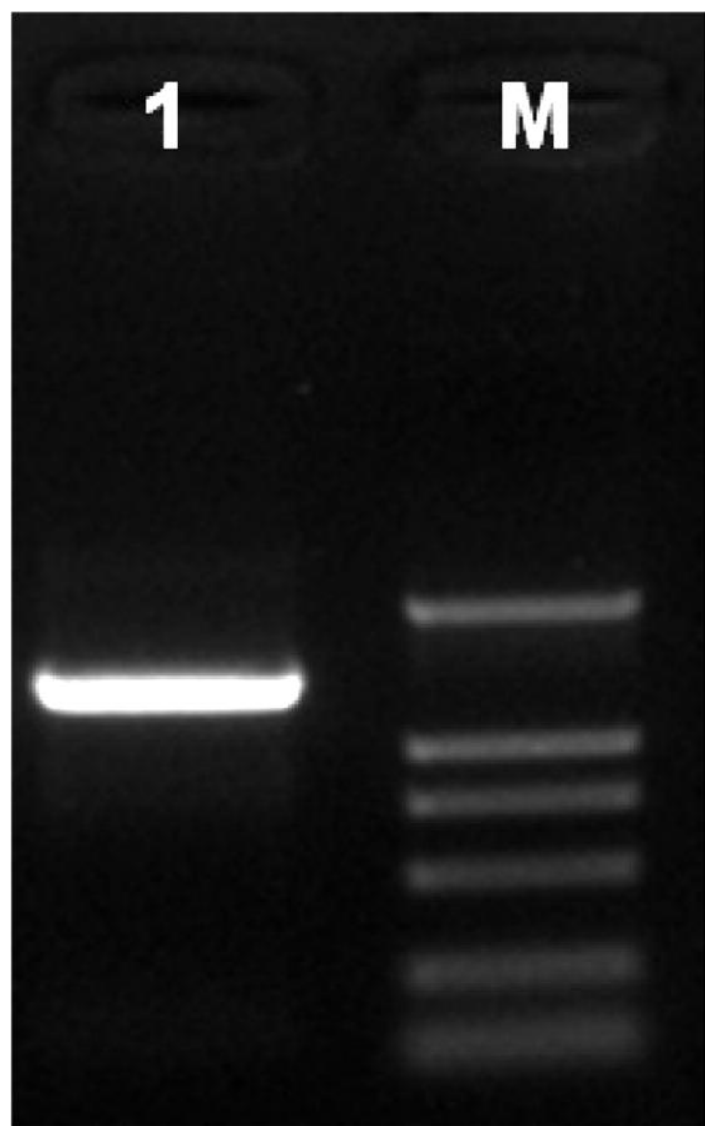

Figure 2. TSLC1 mRNA expression in the TTG with RT-PCR. M - DL2.000 DNA. Marker 1 - TSLC1 mRNA (about $1400 \mathrm{bp}$ ) 

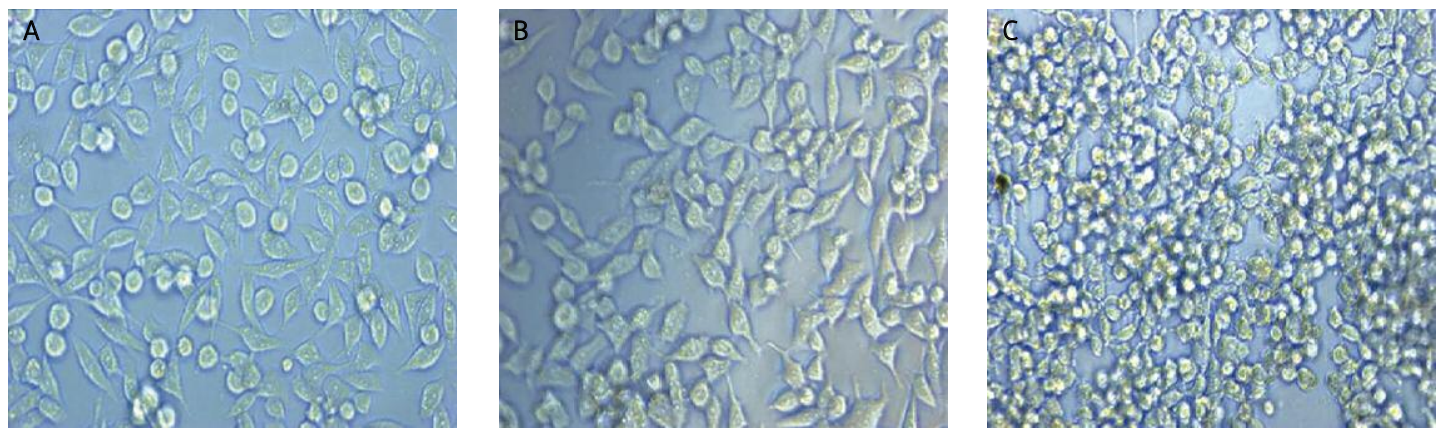

Figure 3. Morphological changes $48 \mathrm{~h}$ after transient transfection. A - UTG and B - MG showed polygonal and spindle cells, packed closely together between cells and eugonic growth, C - TTG showed round and oval-shaped cells, clustered into a mass, scattered between cell mass and poor state

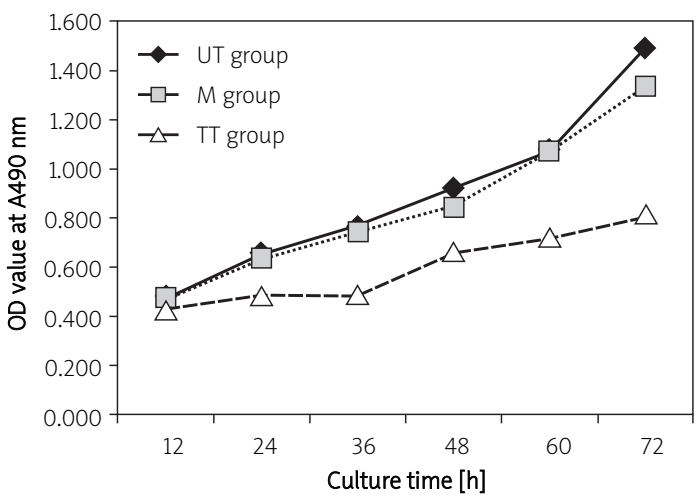

Figure 4. Inhibition of proliferation by TSLC1 in Eca109 cells. After transient transfection, the cell proliferation of TTG was slower than MG and UTG. Cell proliferation inhibition was measured by MTT method
Table I. OD values of the three groups at different time points $(\bar{x} \pm s)$

\begin{tabular}{|lccc|}
\hline $\begin{array}{l}\text { Culture } \\
\text { time }[\mathrm{h}]\end{array}$ & \multicolumn{3}{c|}{ Groups } \\
\cline { 2 - 4 } & TG & MG & UTG \\
\hline 12 & $0.427 \pm 0.033$ & $0.470 \pm 0.032$ & $0.466 \pm 0.027$ \\
\hline 24 & $0.479 \pm 0.037^{\mathrm{a}, \mathrm{b}}$ & $0.634 \pm 0.044$ & $0.649 \pm 0.034$ \\
\hline 36 & $0.487 \pm 0.069^{\mathrm{a}, \mathrm{b}}$ & $0.742 \pm 0.021$ & $0.766 \pm 0.051$ \\
\hline 48 & $0.661 \pm 0.020^{\mathrm{a}, \mathrm{b}}$ & $0.847 \pm 0.048$ & $0.918 \pm 0.083$ \\
\hline 60 & $0.720 \pm 0.012^{\mathrm{a}, \mathrm{b}}$ & $1.072 \pm 0.102$ & $1.070 \pm 0.063$ \\
\hline 72 & $0.815 \pm 0.041^{\mathrm{a}, \mathrm{b}}$ & $1.335 \pm 0.067$ & $1.488 \pm 0.085$ \\
\hline
\end{tabular}

$a_{p}<0.01$, TTG vs. MG, ${ }^{b} p<0.01$, TTG vs. UTG. Data are mean \pm SD of three independent experiments
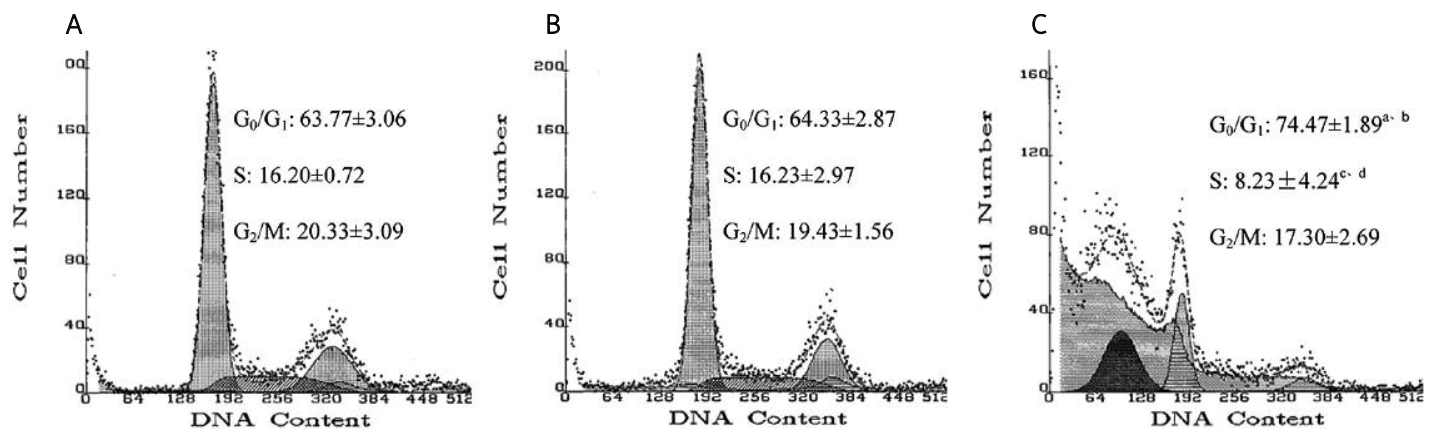

Figure 5. Flow cytometry analysis of cell cycle in Eca109 $48 \mathrm{~h}$ after transient transfection. A - UTG, B - MG, C - TTG. The distribution of the cell cycle was analyzed with propidium iodide (PI) assay

inhibition rate for $36 \mathrm{~h}$ and $72 \mathrm{~h}$ was $34.2 \%$ and $38.8 \%$ respectively, which demonstrated that the cells of TTG were significantly inhibited.

\section{Cell cycle analysis}

Forty-eight hours after transfection, the cells of each group were analyzed by using FCM to analyze alterations in cell cycle distribution. The results showed that in G0/G1 phase, TTG $(74.47 \pm 1.89 \%)$ was significantly higher than MG $(64.33 \pm 2.87 \%$, $p<0.01)$ and UTG $(63.77 \pm 3.06 \%, p<0.01)$, while in S phase, TTG $(8.23 \pm 4.24 \%)$ was significantly lower than MG $(16.23 \pm 2.97 \%, p<0.05)$ and UTG $(16.20$ $\pm 0.72 \%, p<0.05$ ) (Figure 5).

\section{Effect of TSLC1 on apoptosis of Eca109 cells}

Forty-eight hours after transfection, the rate of apoptotic cells and dead cells was analyzed with Annexin V-FITC/PI double-labeled FCM. For apoptosis rate, TTG $(15.5 \pm 5.11 \%)$ was significantly high- 
A

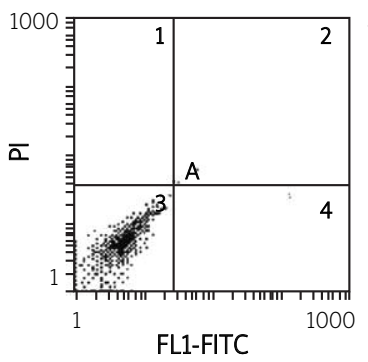

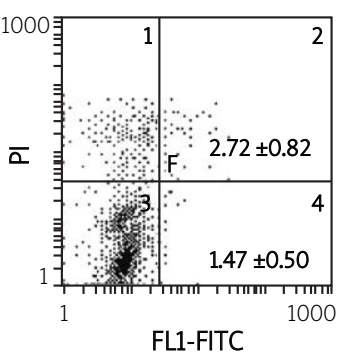

C

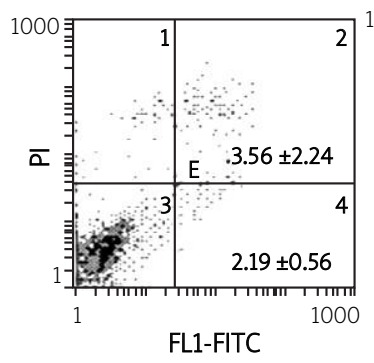

D

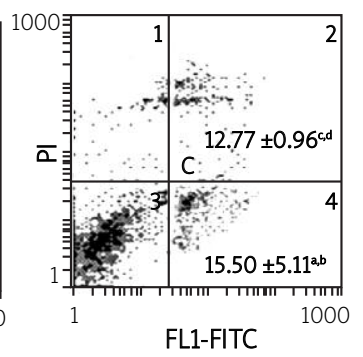

$a_{p}<0.01$, TTG VS MG, ${ }^{b_{p}}<0.01$, TTG VS UTG, ${ }^{c} p<0.01$, TTG VS MG, ${ }^{d} p<0.01$, TTG VS UTG

Figure 6. Effect of TSLC1 on apoptosis rate of Eca109 cells $48 \mathrm{~h}$ after transient transfection. A-cell-free control diagram, B - UTG, C - MG, D - TTG. Percentage of apoptotic cells was measured by flow cytometry after Annexin-V/propidium iodide $(\mathrm{PI})$ staining. 2 represented cell apoptosis rate; 4 represented cell death rate

er than MG $(2.19 \pm 0.56 \%, p<0.01)$ and UTG $(1.47$ $\pm 0.50 \%, p<0.01)$. For death rate, TTG $(12.77$ $\pm 0.96 \%)$ was significantly higher than MG $(3.56$ $\pm 2.24 \%, p<0.01)$ and UTG $(2.72 \pm 0.82 \%, p<0.01)$ (Figure 6).

\section{Discussion}

The TSLC1 gene, which has been confirmed as a tumor suppressor gene, shows low or loss of expression in a variety of tumor cells. The TSLC1 gene encodes nectin-like protein 2 ( $\mathrm{Necl}-2)$, which can regulate adhesion between epithelial cells with other nectins, helping immune cells to recognize and kill tumor cells, or inhibit tumorgenesis. Natural killer (NK) cells and CD8+ T cells also can identify Necl-2 through class I restricted T-cell-associated molecule (CRTAM) receptor. In vivo, the interaction of CRTAM and Necl-2 promoted NK cells repelling $\mathrm{Necl}-2$ positive tumor cells, while in vitro, CRTAMNecl-2 stimulated NK cells releasing a cytotoxic effect and CD8+ T cells excreting INF- $\gamma$ to inhibit tumor growth [12]. Therefore, TSLC1 plays an important role in tumor immune surveillance. Low or lack of expression of TSLC1 can make tumor cells escape from the immune response. Mao et al. [13] transfected TSLC1 expression adenovirus vector into nonsmall cell lung cancer (NSCLC) A549 cell line, and found that $60 \%$ of cells showed apoptosis as time and TSLC1 accumulated. It also activated caspase 3 at the same time. Surace et al. [14] found that TSLC1 could effectively inhibit malignant meningiomas IOMM-Lee cell line proliferation. In this study, we transiently transfected the TSLC1 gene into human esophageal carcinoma Eca109 cells, then the strongest fluorescence appeared in TTG and MG $48 \mathrm{~h}$ after transfection, while UTG showed no fluorescence, which indicated expression of the EGFP gene. In order to prove expression of the TSLC1 gene more objectively, we analyzed the TSLC1 mRNA of TTG with RT-PCR, and the band was located at about
$1400 \mathrm{bp}$, as we expected. Thus the TSLC1 gene had been transfected into Eca109 cells successfully.

There is another mechanism of the TSLC1 gene that inhibits tumor cell proliferation, arresting cell cycle progress and inducing cell apoptosis. Sussan et al. [15] constructed cell line 12.2 by introducing a YAC derivative containing the TSLC1 gene into non-small cell lung cancer cell line A549, and found that the 12.2 cell line showed significant accumulation in $G_{0} / G_{1}$ phase and absence in $S$ and $G_{2} / M$ phase compared with A549. Thus it suggested that TSLC1 was a negative factor in the cell cycle, which delayed progression into $S$ phase and arrested the cell cycle in $\mathrm{G}_{1} / \mathrm{S}$ phase. In the current study, Eca109 cells were inhibited by the TSLC1 gene compared with the other two groups according to morphological changes. The MTT assay showed that the proliferation rate of TTG is significantly lower than MG and UTG; moreover, as we can see in cell proliferation curves, TTG is significantly lower than the other two groups. Cell cycle analysis showed that the cells of TTG in $\mathrm{G}_{0} / \mathrm{G}_{1}$ phase were significantly more numerous than MG and UTG $48 \mathrm{~h}$ after transfection, while in S phase, the cells of TTG were the least numerous, which indicates that the restingphase cells increase significantly and mitotic cells decrease in the TTG. Thus TSLC1 could interfere with Eca109 cells' cell cycle progression in $G_{1} / S$ phase arrest. In order to explore whether the TSLC1 gene has an apoptotic effect on Eca109, we introduced the Annexin-V/PI double staining method. Fortyeight hours after transfection, the apoptosis rate was $15.5 \%$ in TTG, which was significantly higher than MG (2.19\%) and UTG (1.47\%). Our result is similar to other studies about TSLC1 of lung cancer cells [13], hepatocellular cancer cells [9], malignant meningiomas cells [14] and prostate cancer cells [16]. Therefore TSLC1 could induce apoptosis in Eca109 cells and increase cell death.

In conclusion, the TSLC1 gene can inhibit proliferation, regulate the cell cycle, and induce apopto- 
sis of Eca109 cells. The TSLC1 gene may activate the cell apoptosis process during the occurrence and development of esophageal cancer. The potent antitumor capacity of TSLC1 suggested that it could be a promising new experimental anticancer method in human esophageal carcinoma treatment. In the present study, the transient transfection method has gene expression instability that may affect the results to some extent. Thus, the mechanism of the TSLC1 gene in esophageal cancer still needs further studies, providing more adequate evidence for feasibility of gene therapy.

\section{Acknowledgments}

Qi-Lian Liang and Bi-Rong Wang contributed equally. Funding: Science and Technology Planning Project of Guangdong Province, China (No. 2007B031513003). Project supported by Science and Technology Planning Project of Guangdong Province, China (No. 2007B031513003).

\section{References}

1. Kuramochi M, Fukuhara H, Nobukuni T, et al. TSLC1 is a tumor-suppressor gene in human non-small-cell lung cancer. Nat Genet 2001; 27: 427-30.

2. Liang QL, Chen GQ, Li ZY, Wang BR. Function and histopathology of a cell adhesion molecule TSLC1 in cancer. Cancer Invest 2011; 29: 107-12.

3. Wang J, Zhang H, Bai W, Li L, Bian K, Cheng S. Promoter hypermethylation and mRNA expression of TSLC1 gene in laryngeal squamous cell carcinoma. J Fourth Mil Med Univ 2007; 28: 651-3.

4. Yang YX, Yang AH, Yang ZJ, Wang ZR, Xia XH. Involvement of tumor suppressor in lung cancer 1 gene expression in cervical carcinogenesis. Int J Gynecol Cancer 2006; 16: 1868-72.

5. Yang G, He W, Cai M, et al. Loss/down-regulation of tumor suppressor in lung cancer 1 expression is associated with tumor progression and is a biomarker of poor prognosis in ovarian carcinoma. Int J Gynecol Cancer 2011; 21: 486-93.

6. Heller G, Geradts J, Ziegler B, et al. Downregulation of TSLC1 and DAL-1 expression occurs frequently in breast cancer. Breast Cancer Res Treat 2007; 103: 283-91.

7. Lung HL, Cheung AK, Xie D, et al. TSLC1 is a tumor suppressor gene associated with metastasis in nasopharyn geal carcinoma. Cancer Res 2006; 66: 9385-92.

8. Ando K, Ohira M, Ozaki T, et al. Expression of TSLC1, a candidate tumor suppressor gene mapped to chromosome $11 q 23$, is downregulated in unfavorable neuroblastoma without promoter hypermethylation. Int J Cancer 2008; 123: 2087-94.

9. Qin L, Zhu W, Xu T, et al. Effect of TSLC1 gene on proliferation, invasion and apoptosis of human hepatocellular carcinoma cell line HepG2. J Huazhong Univ Sci Technolog Med Sci 2007; 27: 535-7.

10. Ito T, Shimada Y, Hashimoto Y, et al. Involvement of TSLC1 in progression of esophageal squamous cell carcinoma. Cancer Res 2003; 63: 6320-6.

11. Liang QL, Wang BR, Li ZY, Chen GQ, Zhou Y. Construction of eukaryotic expression vector of TSLC1 gene. Arch Med Sci 2011; 7: 579-85.

12. Boles KS, Barchet W, Diacovo T, Cella M, Colonna M. The tumor suppressor TSLC1/NECL-2 triggers NK-cell and CD8
T-cell responses through the cell-surface receptor CRTAM. Blood 2005; 106: 779-86.

13. Mao X, Seidlitz E, Truant R, Hitt M, Ghosh HP. Re-expression of TSLC1 in a non-small-cell lung cancer cell line induces apoptosis and inhibits tumor growth. Oncogene 2004; 23: 5632-42.

14. Surace El, Lusis E, Murakami Y, Scheithauer BW, Perry A, Gutmann DH. Loss of tumor suppressor in lung cancer-1 (TSLC1) expression in meningioma correlates with increased malignancy grade and reduced patient survival. J Neuropathol Exp Neurol 2004; 63: 1015-27.

15. Sussan TE, Pletcher MT, Murakami Y, Reeves RH. Tumor suppressor in lung cancer 1 (TSLC1) alters tumorigenic growth properties and gene expression. Mol Cancer 2005; 4: 28.

16. Fukuhara H, Kuramochi M, Fukami T, et al. Promoter methylation of TSLC1 and tumor suppression by its gene product in human prostate cancer. Jpn J Cancer Res 2002; 93: 605-9. 